\title{
TRM strengthening of masonry arches: An experimental investigation on the effect of strengthening layout and textile fibre material
}

\author{
Florentia A. Kariou ${ }^{\mathrm{a}}$, Savvas P. Triantafyllou ${ }^{\mathrm{a}, *}$, Dionysios A. Bournas ${ }^{\mathrm{b}}$ \\ ${ }^{a}$ Centre for Structural Engineering and Informatics, The University of Nottingham, Nottingham, NG7 2RD, UK \\ ${ }^{b}$ European Commission, Joint Research Centre (JRC), Ispra, Italy
}

\begin{abstract}
The effectiveness of the textile reinforced mortar (TRM) strenghtening technique on clay brick masonry arches is investigated. Eight half-scaled specimens were subjected to static monotonic loading applied at the quarter length of the span until failure. Experimental parameters comprised the number of TRM layers, the textile fibre material, and the strengthening layout, i.e., application in either the intrados or the extrados. The experimental results are discussed in terms of the resulting failure mechanisms and conclusions are drawn with regards to the strength and deformability achieved through each strengthening strategy.
\end{abstract}

Keywords: Textile Reinforced Mortar, Masonry Arch, Strengthening

\section{Introduction}

Masonry arches have been widely used in engineering practice as an effective structural system to span medium to large openings. Arches and barrel vaults have been utilised in historical structures of extreme cultural importance, residential ${ }^{25}$ buildings, and also constitute a substantial part of rail and transport infrastructure worldwide. Unreinforced masonry arches are often subjected to asymmetric loading due to, e.g., seismic excitation and uneven soil settlement at bridge abut- ${ }^{30}$ ments. Furthermore, they are susceptible to brittle failure modes often leading to structural degradation, and loss of human life.

Within this setting, structural strengthening is required for structures to withstand increased op- 35 erational loads due to the heavy cargo movements and also avoid catastrophic collapse events, see, e.g., Mexico (2017), Central Italy (2016-2017),

\footnotetext{
*Corresponding author

Email address:

savvas.triantafyllou@nottingham.ac.uk (Dionysios
}

A. Bournas) (2014), Chile (2010), and Indonesia (2004).

Unreinforced masonry structures behave poorly under tension, therefore several conventional strengthening techniques have been employed to increase their overall response and deformation capacity. Typical techniques vary from the application of center-cored reinforcement, anchorage between diaphragms and walls and tension ties [1] to the application of ferrocement, grout injections, concrete jacketing and repair of mortar joints [see, e.g., 2].

FRP employed in strips [3, 4, 5], laminates [6, 7, 8], sheets [5] or tendons [9] can efficiently upgrade existing masonry structures in terms of load and deformation capacity providing high tensile strength with the ability to adapt in curved surfaces. Several drawbacks of FRP application were reported with respect to the epoxy resin degradation in terms of stiffness and strength close to the $50-120{ }^{\circ} \mathrm{C}$ ) [10, 11, 12, 13]. Raoof and Bournas [13] reported that the bond strength of FRP decreased significantly at $150^{\circ} \mathrm{C}$. In higher level of 
temperatures $\left(250,300-400{ }^{\circ} \mathrm{C}\right)$ the epoxy resin ing heat, smoke and toxic gases [10, 14].

Over the past fifteen years a new retrofitting technique, i.e., the Textile Reinforced Mortar 95 (TRM), has emerged as an efficient and low environmental impact alternative to already established strengthening procedures. TRM involve inorganic binders (e.g. cementitious mortars) in combination with open-mesh textile fabrics (e.g.100 carbon, glass and basalt) impregnated within the matrix. Fiber Reinforced Cementitious Matrix (FRCM) acronym is also used in several scientific works instead of the TRM [15, 16]. A beneficial effect of TRM composites is that they canos maintain their structural properties up to $400{ }^{\circ} \mathrm{C}$ [13, 17. Two state-of-the-art reviews indicated very recently most of the successful strengthening applications of TRM for concrete [18] and masonry structures [19].

Extensive experimental work has been directed sonry arches, which were strenothened with either FRP or TRM and tested under static monotonic load at the quarter length of the span. Royles andi15 Hendry 20] reported failure modes which comprise the formation of three or four hinges of the unreinforced full-scale masonry arch bridges. It was also found that the strengthening configuration (extrados and intrados) significantly affectedı20 the performance of strengthened arches in terms of maximum load, deformation capacity, and failure mode.

The most common failure mechanism in case of the extrados strengthening of masonry archesi25 with FRP or TRM materials, was sliding along a mortar joint at the supports [6, 3, 4, 7, 21, 22, 23, 24. Specimens strengthened at the intrados with FRP or TRM composite materials mainly failed due to debonding of the strengthening material from the masonry substrate at the loaded cross-section [6, 3, 4, 7, 25, 26, 27]. However, a

variety of different failure modes has also been re-130 ported in the literature [24, 28, 21]. This is due to the uncertainties pertinent to construction material itself and its response under combined stress states; hence, the need for further experimental

work is identified to enable better understanding of the response of strengthened masonry arches.

The number of experimental works on the use of TRM as strengthening material of masonry arches is rather limited, with the majority of studies being published after 2015 [21, 23, 24, 22, 27, 28, 29]. Hence, considering the variability of the investigated parameters examined in the literature, further experimental work is required to highlight the mechanical response of such structures. To this point, the materials that have been used so far for the extrados were basalt TRM, glass TRM, polyparaphenylene benzobisoxazole (PBO) -FRCM, Steel Reinforced Grout (SRG) and for the intrados PBO-FRCM, Carbon Fiber (C)FRCM and SRG.

This paper presents an extensive experimental study on the response of masonry arches strengthened with TRM composites. Investigated parameters comprise the strengthening material, i.e., coated basalt and coated glass, the amount of textile reinforcement used and the strengthening layout, i.e., intrados and extrados strengthening. Coated glass has been found to significantly enhance the out-of-plane response of masonry walls compared to uncoated glass textile reinforcement [30, 31]. To the authors' knowledge, this is the first time that a comparative study between all the aforementioned parameters is attempted within a single experimental campaign.

This manuscript is organized as follows. The experimental program and the properties of the materials used are presented in Section 2. The experimental results are described in Section 3 and discussed in Section 4 ,

\section{Experimental Program}

\subsection{Test specimens and investigated parameters}

Eight half-scaled masonry arches specimens were built with a $2.0 \mathrm{~m}$ span, $0.5 \mathrm{~m}$ rise, 0.1025 $\mathrm{m}$ thickness, and $0.44 \mathrm{~m}$ width. Half-scale was selected to better reflect typical geometries of masonry arches also as suggested in the relevant literature, see, e.g., [25]. Solid clay bricks were used along with a general purpose masonry ce- 
ment mortar of $10 \mathrm{~mm}$ thickness for both bed and head joints.

The key investigated parameters of this study were: (a) the textile fibre material used, i.e., coated glass and coated basalt, (b) the number of TRM layers, and (c) the strengthening configuration (intrados versus extrados). The control specimen $(\mathrm{CON})$ was not strengthened. The remaining 7 specimens were strengthened at either their internal or external surface, i.e., intrados and extrados, respectively. Three and seven layers of coated glass or coated basalt TRM were applied as strengthening material at the intrados or the extrados of each masonry arch. The case of seven layers of coated glass and basalt TRM is considered as these have been shown to have an axial stiffness equivalent to a single carbon TRM layer [30. This can hence provide a comparative basis with previous works where the case of carbon fibre textile material is considered, [see, e.g., 32]. The case of three layers is further considered to investigate the influence of the amount of reinforcement when this is practically halved. The glass textile fibre material was coated using an in-house coating procedure whereas coated basalt textile-fibre material was a commercially coated material. The in-house coating procedure employed is discussed in Section 2.2.

The specimens together with the corresponding investigated parameters are summarized in Table 1 . The notation adopted for the strengthened arches is MN_Cf, where M denotes the fibre textile material ( $\mathrm{G}$ for coated glass and B for coated basalt), $\mathrm{N}$ denotes the number of TRM layers (3 and 7) and Cf denotes the strengthening configuration (E for Extrados and I for Intrados).

It is of interest to note that, although attempted, the application of 7 layers of basalt textile fibre material at the intrados of the arches was not feasible; due to the the large mesh spacing of $25 \mathrm{~mm}$ the textile fibre material was slipping while the mortar was still in fresh state.

\subsection{Materials}

The arches were built using solid clay bricks with UK typical nominal dimensions of $215 \mathrm{x}$ $102.5 \times 65 \mathrm{~mm}$. The average value of the compres-

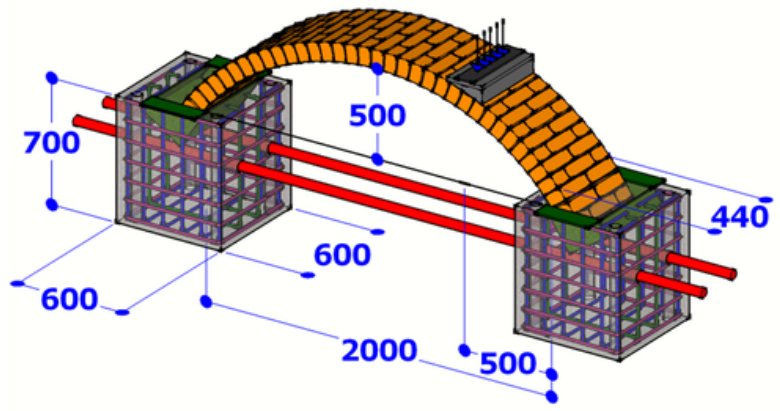

(a)

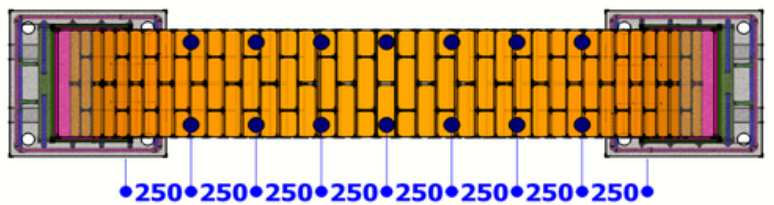

(b)

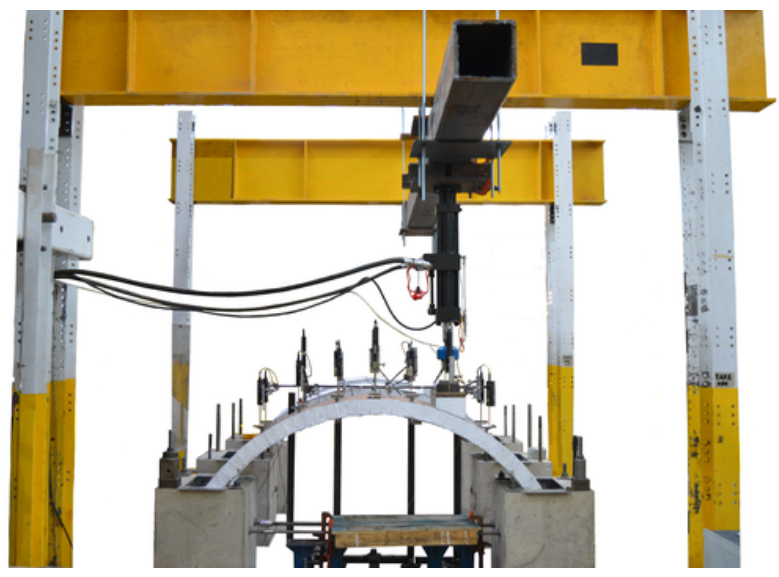

(c)

Figure 1: Experimental setup - all units are in mm (a) geometry and load configuration (b) plan view and position of displacement transducers (c) 


\begin{tabular}{ccccc}
\hline Specimen & TRM material & Strengthened at the & Number of TRM layers & $\begin{array}{c}\text { TRM thickness } \\
{[\mathbf{m m}]}\end{array}$ \\
\hline CON & & - & 3 & 7 \\
\hline G3_I & Coated glass & Intrados & 7 & 9 \\
\hline G7_I & Coated glass & Intrados & 3 & 9 \\
\hline B3_I & Coated basalt & Intrados & 3 & 7 \\
\hline G3_E & Coated glass & Extrados & 7 & 9 \\
\hline G7_E & Coated glass & Extrados & 3 & 9 \\
\hline B3_E & Coated basalt & Extrados & Yes & Yes \\
\hline B7_E & Coated basalt & Extrados & No & 13 \\
\hline
\end{tabular}

Table 1: Specimens and investigated parameters

sive strength was determined in a perpendicular direction to bed $(215 \times 102.5 \mathrm{~mm})$ and stretcher faces $(215 \times 65 \mathrm{~mm})$ of the bricks was $21.2 \mathrm{MPa}$ according to BS [33]. The mortar joint was pre-220 pared with a 1:4 cement to sand mix for both head and bed joints. The water to (cement + sand) ratio was chosen to be 0.25 after trial mixes to achieve the desired workability.

Joint and strengthening mortar prisms (40 $\mathrm{x}^{225}$ $40 \times 160 \mathrm{~mm}$ ) were tested for each specimen, under flexure and compression per the EN [34] specifications. For this purpose, three prisms were tested in three-point bending and the ruptured segments obtained were used to define the uniax $^{230}$ $40 \mathrm{~mm}$. Table 2 presents the mean values of the compressive and tensile strength. The variability was similar for the compressive strength of both casting and strengthening mortar and marginally ${ }^{235}$ any case, the observed variabilities did not affect the observed failure modes.

Three masonry wallets of dimensions 450 x 450 x $65 \mathrm{~mm}$ (length $\mathrm{x}$ height $\mathrm{x}$ width) were tested ${ }^{240}$ under compression in a perpendicular direction to the bed joints per EN [35], after 28 days of their construction. The wall assemblage deformation was captured through two potentiometers, positioned halfway on both sides at a gauge length ${ }^{245}$ of $250 \mathrm{~mm}$. The mean value of the compressive strength determined equal to $9.7 \mathrm{MPa}$ while the secant elastic modulus at $0 \%$ to $30 \%$ of the maximum stress defined equal to 2.5 GPa.

Strengthening of masonry arches was performed using either coated glass or coated basalt textile fibre material as presented in Fig. 2. The250 corresponding material properties, according to the manufacturer data sheets, are shown in Table 3. The nominal thickness of the textile fibre material shown in Table 3 is defined according to the equivalent smeared distribution of fibres.

The glass textile fibre material was coated inhouse using a two part commercial epoxy resin of mixing ratio $2: 1$ by weight. The elastic modulus and tensile strength of the epoxy resin were $1.8 \mathrm{GPa}$ and $37 \mathrm{MPa}$, respectively as per the manufacturer datasheets. On the other hand, coated basalt fibre-textile was a commercial product manufactured with 10\% bituminous binder. The epoxy resin was applied on the dry textile using a plastic roll. The textile was then left to cure for two days before strengthening was applied. It should be noted that the glass fibre mesh size and the corresponding application procedure ensured that the roving spacings were not filled/ covered by resin. The average amount of the epoxy resin used for the impregnation was $180 \mathrm{~g} / \mathrm{m}^{2}$.

The strengthening mortar comprised an inorganic dry binder (cement + sand) with polymers at a ratio of 8:1 by weight. The mean values of the flexural and compressive strength were determined on the day of testing and found equal to 9.8 $\mathrm{MPa}$ and $32.8 \mathrm{MPa}$, respectively. The mortar mixture contained water in a water to cementitious material ratio equal to 0.23 by weight.

\subsection{Strengthening procedure}

TRM strengthening was implemented according to the following procedure:

(i) Dust from the surface to be strengthened was removed using air pressure. 


\begin{tabular}{|c|c|c|c|c|}
\hline \multirow[t]{3}{*}{ Specimens } & \multicolumn{2}{|c|}{ Casting mortar } & \multicolumn{2}{|c|}{ Strengthening mortar } \\
\hline & Compressive & Tensile & Compressive & Tensile \\
\hline & $\begin{array}{c}\text { Strength } \\
\text { [MPa] }\end{array}$ & $\begin{array}{l}\text { Strength } \\
\text { [MPa] }\end{array}$ & $\begin{array}{c}\text { Strength } \\
{[\mathrm{MPa}]}\end{array}$ & $\begin{array}{l}\text { Strength } \\
\text { [MPa] }\end{array}$ \\
\hline $\mathrm{CON}$ & 9.2 & 3.5 & & \\
\hline G3_I & 9.0 & 2.8 & 38.6 & 9.2 \\
\hline G7_I & 8.1 & 3.0 & 30.9 & 8.6 \\
\hline B3_I & 7.2 & 2.5 & 32.1 & 10.2 \\
\hline G3_E & 6.8 & 2.6 & 37.4 & 10.2 \\
\hline G7_E & 6.7 & 2.7 & 37.1 & 10.5 \\
\hline B3_E & 9.7 & 2.8 & 25.6 & 8.9 \\
\hline B7_E & 7.8 & 2.8 & 28.2 & 11.1 \\
\hline Monn volu & 8.1 & 2.8 & 32.8 & 9.8 \\
\hline Mean value & $\left(1.2^{*} / 0.14^{* *}\right)$ & $\left(0.3^{*} / 0.11^{* *}\right)$ & $\left(5.0^{*} / 0.15^{* *}\right)$ & $\left(0.9^{*} / 0.09^{* *}\right)$ \\
\hline
\end{tabular}

Table 2: Casting and strengthening mortar

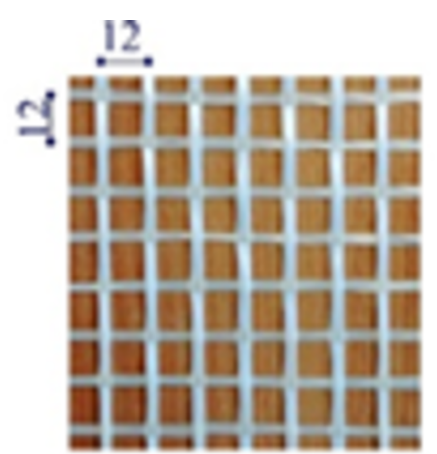

(a)

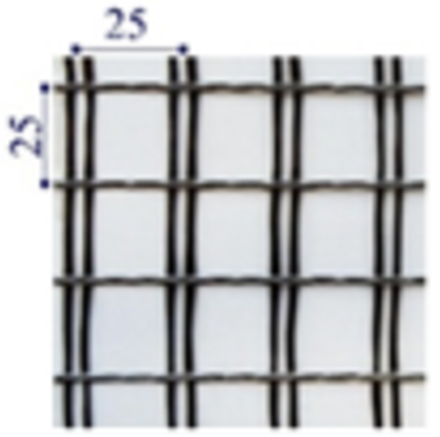

(b)

Figure 2: (a) Coated glass and (b) Coated basalt textile materials and corresponding mesh sizes considered in this study

\begin{tabular}{|c|c|c|c|c|c|}
\hline Material & $\begin{array}{l}\text { Weight } \\
{\left[\mathrm{g} / \mathrm{m}^{2}\right]}\end{array}$ & $\begin{array}{c}\text { Thickness } \\
\text { (Nominal) } \\
\text { [mm] }\end{array}$ & $\begin{array}{c}\text { Tensile } \\
\text { strength } \\
{[\mathrm{MPa}]}\end{array}$ & $\begin{array}{c}\text { Young's } \\
\text { modulus* } \\
{[\mathrm{GPa}]}\end{array}$ & $\begin{array}{c}\text { Axial } \\
\text { Stiffness }^{* *} \\
{[\mathrm{~N} / \mathrm{mm}]}\end{array}$ \\
\hline Glass & 220 & 0.044 & 1400 & 74 & 3.26 \\
\hline Basalt & 220 & 0.037 & 1351 & 89 & 3.30 \\
\hline
\end{tabular}

Table 3: Textile material properties 
(ii) After dampening the specimen, the mortar was applied to cover the entire surface of the masonry arch.

(iii) One layer of the fibre textile was impregnated into the mortar using hand pressure (Fig. 3a).

(iv) The textile was completely covered by one layer of mortar. The described procedure was repeated for each additional TRM layer.

\subsection{Experimental setup and procedure}

A vertically positioned servo-hydraulic actuator of $100 \mathrm{kN}$ capacity was fastened to a stiff steel reaction frame at the quarter length of the span as shown in Fig. 1c. The load was applied monotonically under displacement control at a rate of $0.005 \mathrm{~mm} / \mathrm{s}$ and $0.015 \mathrm{~mm} / \mathrm{s}$ for the control and strengthened specimens, respectively. The load(approximately equal to $1 \mathrm{~mm} / \mathrm{sec}$ ) is typical for static tests on masonry and concrete structures. A lower rate was chosen for the control specimen to accommodate for its significantly lower strength and deformability. The masonry arches were fixed on concrete blocks. The latter were tied to the strong floor via steel threaded rods. The concrete blocks were further tied together to prevent longitudinal displacements using two steel rods as presented in Fig. 1a. Fourteen displacement transducers were positioned every $250 \mathrm{~mm}$ lengthwise to measure the vertical displacement profile of the arch as shown in Fig. 1b. Data was collected at a frequency of $4 \mathrm{~Hz}$, synchronised and

tion system.

\section{Experimental Results}

The load-displacement response plots for all specimens are presented in Fig. 4a. The data

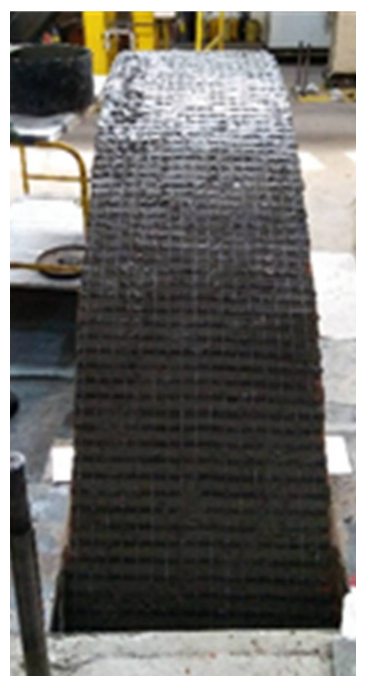

(a)

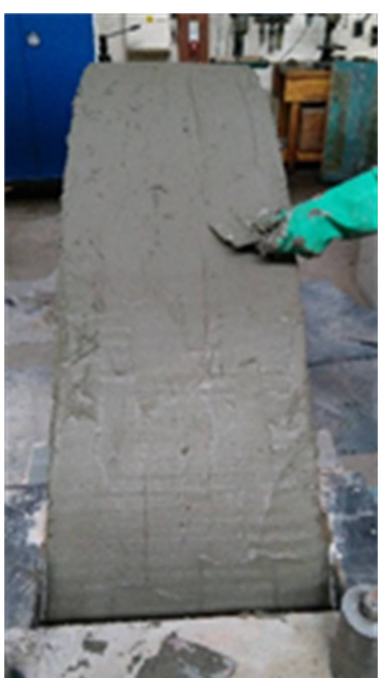

(b)

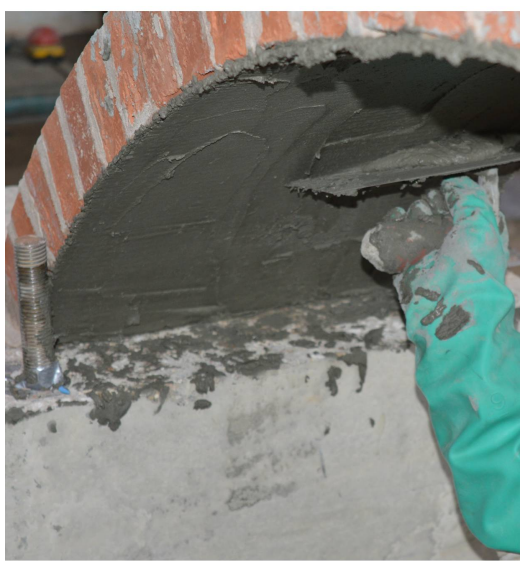

(c)

Figure 3: (a) Application of basalt textile into the mortar (b) Extrados and (c) Intrados final strengthening configuration 
presented in these plots were obtained from the actuator feedback to the controller. The measurements from the displacement transducers positioned on either side of the actuator (Figure345 1c) were used to confirm that the load was applied uniformly along the width of the arch. Table 4 summarizes the experimental results in terms of the maximum load $P_{\max }$, the displacement at maximum load $d_{m a x}$, the ultimate load ${ }_{550}$ $P_{u l t}$, the displacement at ultimate load $d_{u l t}$, the strength increase ratio defined as $S I R=$ $P_{\max } / P_{C O N}$, the displacement increase ratio defined as $D I R=d_{u l t} / d_{C O N}$ and the observed failure modes. The ultimate load is defined as $P_{u l t 355}$ $=\max \left(0.8 P_{\text {max }}, P_{\text {final }}\right)$, where $P_{\text {final }}$ is the last recorded load value as shown in the Load vs Displacement curves (Fig. 4a). The reported displacements correspond to mean values of the displacement transducers at the position of the actuator. The vertical displacement profiles at $P_{\text {ult }}$ are shown in Fig. 5.

Failure modes varied according to the strengthening configuration, the ratio of the strengthening material, and the fibre-textile material utilised. The control specimen failed in a four-hinge collapse mechanism shown in Fig. 6b; as expected ${ }_{365}$ the four hinges formed in alternate positions of intrados and extrados. The control specimen peak load and the corresponding displacement was $3.2 \mathrm{kN}$ and $0.7 \mathrm{~mm}$, respectively (see Fig. 4b).

The collapse mechanism of G3_I, G7_I, and B3_I (see also, Figs. 7, 8, and 9 respectively) was manifested by the formation of two flexural hinges, shear sliding at the left support and under the point load, followed by debonding of the TRM material from the masonry substrate. The high-375 est $P_{\max }$ was recorded in the case of G7_I and was equal to $41.9 \mathrm{kN}$ with the corresponding displacement $d_{\max }=11.0 \mathrm{~mm}$ (Fig. 4f). The highest $d_{\max }$ amongst the intrados strengthened specimens was recorded for B3_I and was equal to $15.5 \mathrm{~mm}$. $\mathrm{It}_{380}$ should be noted that in this case, masonry crushing preceded shear sliding under the point load.

Specimens G3_E and B3_E failed due to shear sliding at the left support and under the loaded cross-section (Figs. 10, 11). Cracks formed at the385 adjacent mortar joints of the right support and left haunch (Fig. 10). In B3_E a hinge also formed at the right support (Fig. 11e). The highest maximum load among the two specimens was observed in G3_E and was equal to $35.1 \mathrm{kN}$, whereas the highest displacement $\mathrm{d}_{\max }$ was reported for B3_E and was equal to $33.9 \mathrm{~mm}$ (see also Fig. 4e).

Specimens G7_E and B7_E failed due to the formation of two hinges (under the point load and in either of the supports) and due to shear sliding at the mortar joint in either of the supports, see Figs. 12 and 13, respectively. Cracks developed on the left haunch of the TRM surface. The highest value of the maximum load was reported for G7_E and was equal to $62.2 \mathrm{kN}$, whereas the highest displacement value $\mathrm{d}_{\max }$ recorded for $\mathrm{B} 7 \mathrm{E}$ equal to $19.4 \mathrm{~mm}$ (see also Table 4 and Fig. 4f).

\section{Discussion}

\subsection{Overview}

Compared to the control specimen, all strengthened specimens demonstrated increased values of their maximum load and deformation capacity. The maximum $S I R$ was recorded for G7_E, i.e., 19.4 whereas the minimum $S I R$ was recorded for G3_I, i.e., 7.8 as shown in Fig. 14.

Among the specimens strengthened at the extrados, G7_E demonstrated the highest $S I R$, whereas B3_E the lowest, i.e., 9.3. The corresponding $S I R$ s for arches strengthened at the intrados were 13.1 and 7.8 for G7_I and G3_I, respectively.

\subsection{The effect of the textile material}

The utilisation of coated glass textile fibre material resulted in marginally increased values of $P_{\max }$ when compared to the coated basalt specimens. In particular, G3_E and G7_E attained increased maximum loads by $18 \%$ and $15 \%$ when compared to B3_E and B7_E, respectively (see also Fig. 15a). The failure modes in both glass and basalt specimens were similar as reported in Table 4.

In the intrados case, B3_I demonstrated a higher $P_{\max }$ by $23 \%$ compared to G3_I; however the maximum loads recorded in these specimens 


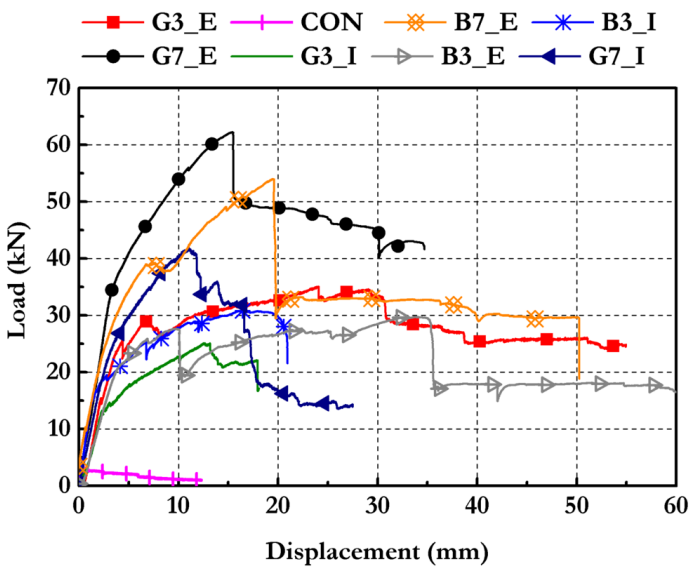

(a) All specimens

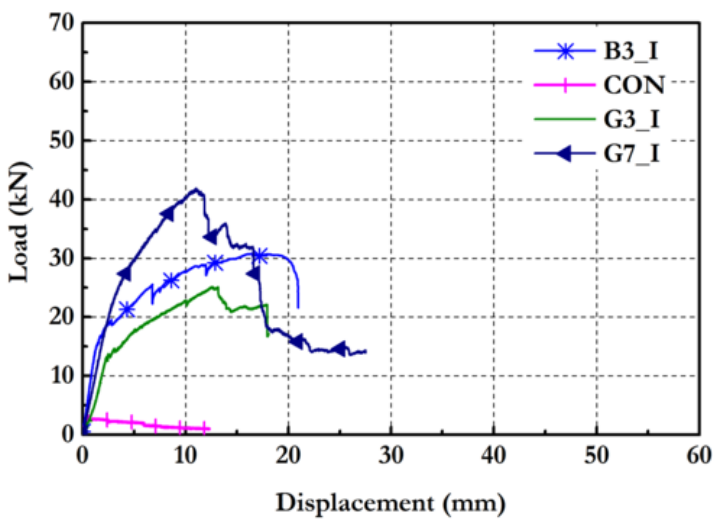

(c) Intrados: 3 and 7 TRM layers

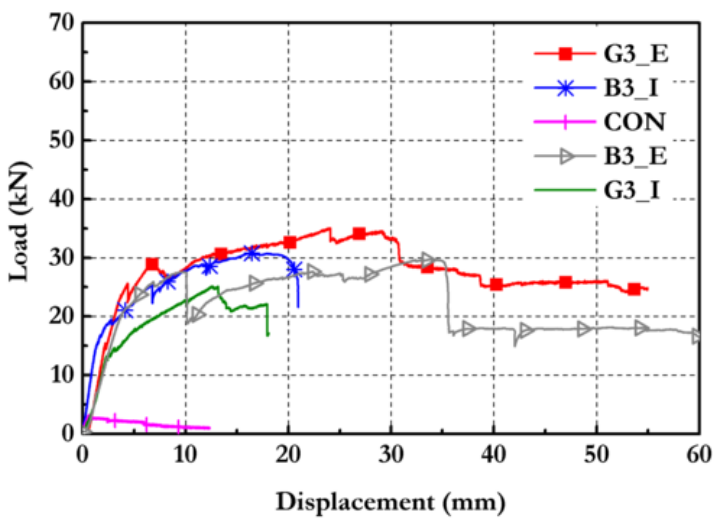

(e) Extrados Vs Intrados 3 TRM layers

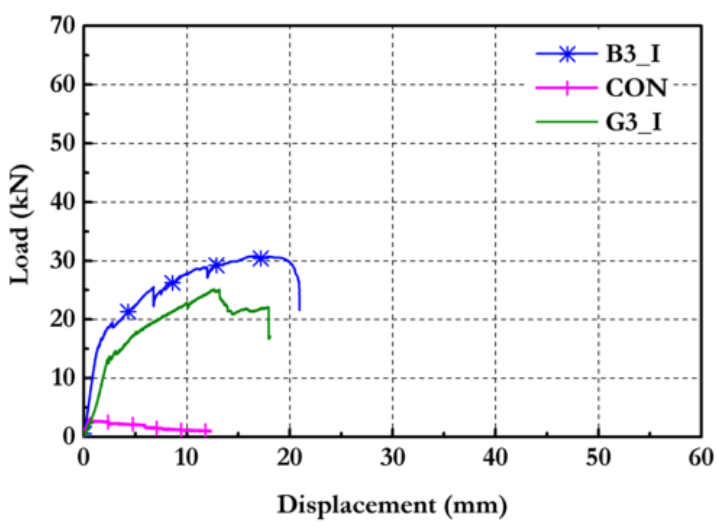

(b) Intrados: Basalt Vs glass textile

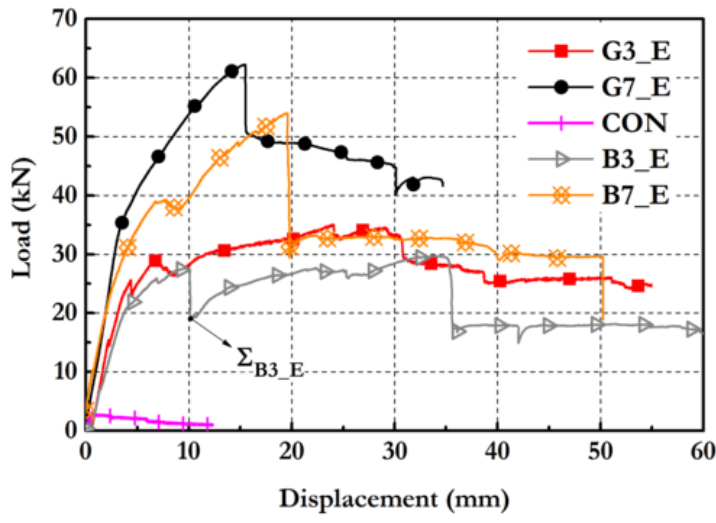

(d) Extrados: 3 and 7 TRM layers

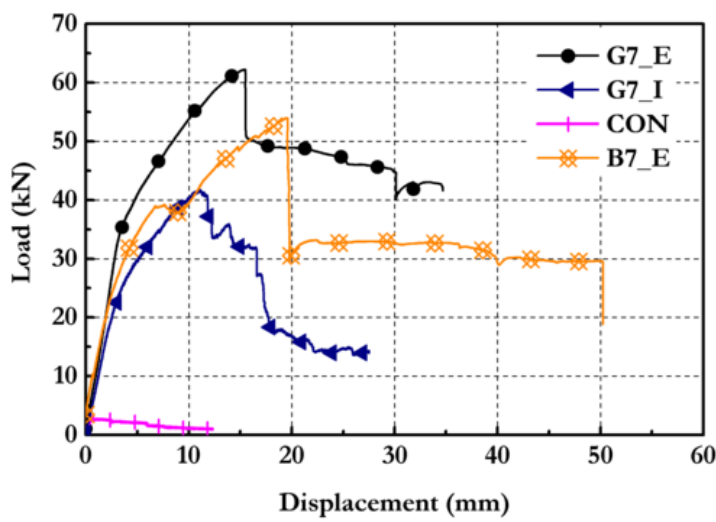

(f) Extrados Vs Intrados 7 TRM layers

Figure 4: Experimental load-displacement curves in terms of the number of layers, textile material, and the position of the strengthening 


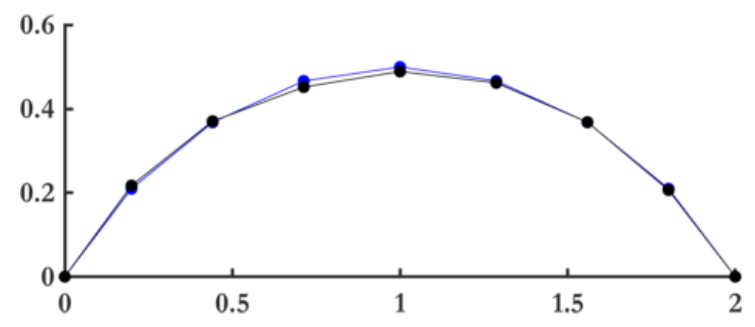

(a) Control Specimen

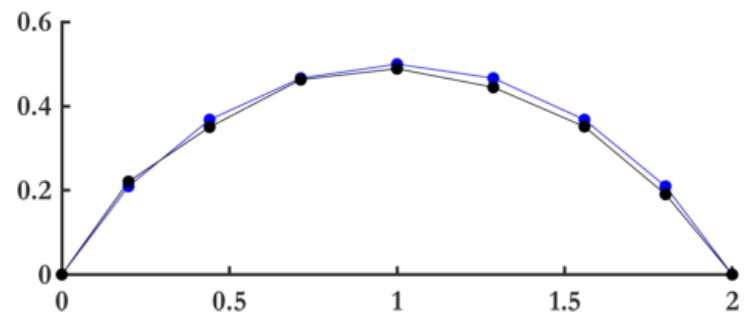

(b) G3_I

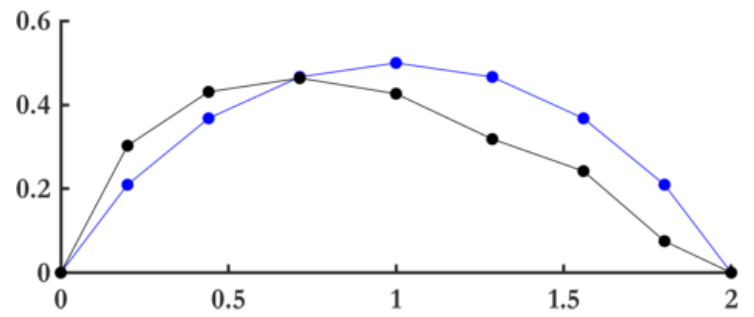

(d) B3_I

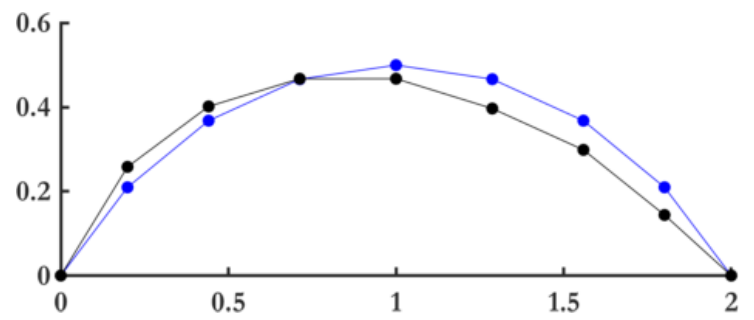

(f) G7_I

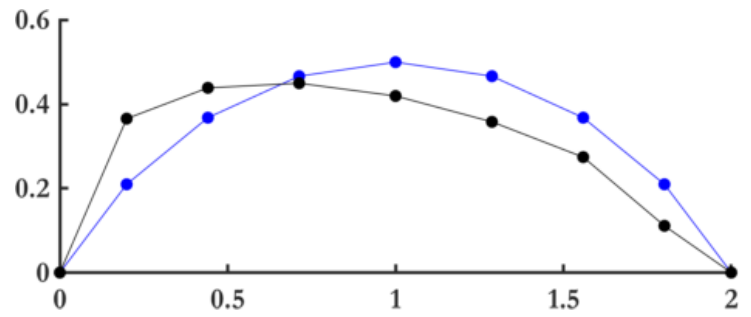

(c) G3_E

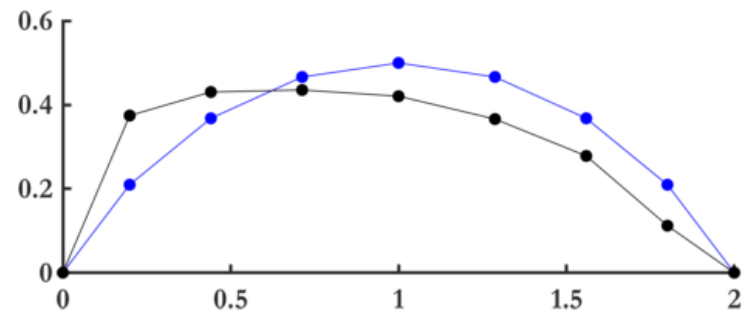

(e) B3_E

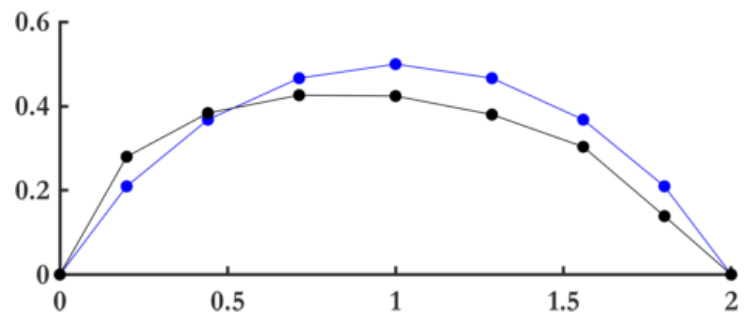

(g) G7_E

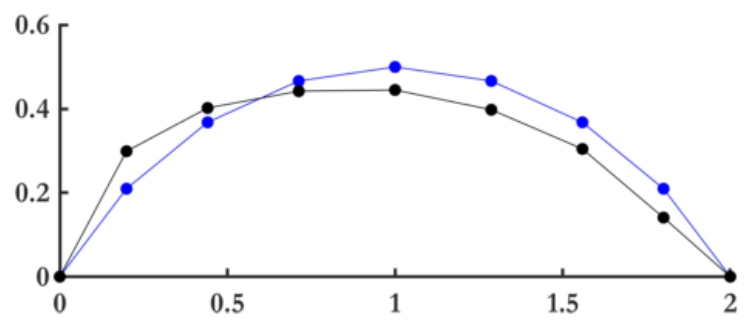

(h) B7_E

Figure 5: Vertical Displacement profiles - Displacements are scaled by a factor of 5 and units are in $\mathrm{m}$ 


\begin{tabular}{|c|c|c|c|c|c|c|c|}
\hline & $\begin{array}{l}P_{\text {max }} \\
{[\mathrm{kN}]}\end{array}$ & $\begin{array}{l}\mathrm{d}_{\max } \\
{[\mathrm{mm}]}\end{array}$ & $\begin{array}{l}\mathrm{P}_{\text {ult }} \\
{[\mathrm{kN}]}\end{array}$ & $\begin{array}{c}\mathrm{d}_{\text {ult }} \\
{[\mathrm{mm}]}\end{array}$ & $S I R$ & $D I R$ & Failure mode \\
\hline $\mathrm{CON}$ & 3.2 & 0.7 & 2.6 & 1.9 & 1.0 & 1.0 & 4-hinge mechanism \\
\hline G3_I & 25.1 & 13.2 & 20.1 & 18.0 & 7.8 & 9.7 & 2 hinges, shear sliding ${ }^{1,2}$ \\
\hline G7_I & 41.9 & 11.0 & 33.5 & 12.4 & 13.1 & 6.7 & 2 hinges, shear sliding ${ }^{1,2}$ \\
\hline B3_I & 30.8 & 16.5 & 24.6 & 21.0 & 9.6 & 11.3 & 2 hinges, masonry crushing, shear sliding ${ }^{1,2,3}$ \\
\hline G3_E & 35.1 & 24.1 & 28.1 & 35.0 & 11.0 & 18.8 & Shear sliding ${ }^{1,4}, \operatorname{cracks}^{5,6}$ \\
\hline G7_E & 62.2 & 15.4 & 49.8 & 16.8 & 19.4 & 9.0 & 2 hinges $^{1,4}$, shear sliding ${ }^{5}$, cracks $^{6}$ \\
\hline B3_E & 29.7 & 33.9 & 23.8 & 35.6 & 9.3 & 19.1 & Shear sliding ${ }^{1,4}$, cracks ${ }^{5,6}$, hinge ${ }^{5}$ \\
\hline B7_E & 54.0 & 19.4 & 43.2 & 19.7 & 16.9 & 10.6 & 2 hinges $^{4,5}$, shear sliding $^{1}$, cracks $^{6}$ \\
\hline
\end{tabular}

${ }^{1}$ left support, ${ }^{2}$ followed by TRM debonding under point load, ${ }^{3}$ partial textile rupture ${ }^{4}$ under point load, ${ }^{5}$ right support, ${ }^{6}$ left haunch

Table 4: Summary of experimental results

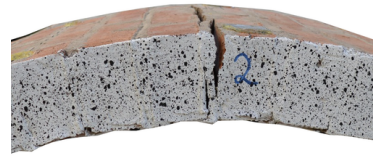

(a) Section 2

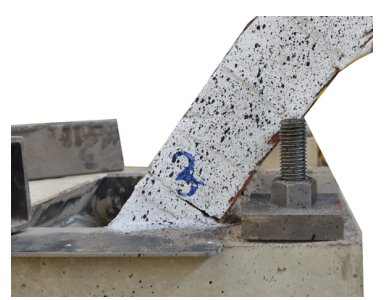

(d) Section 3

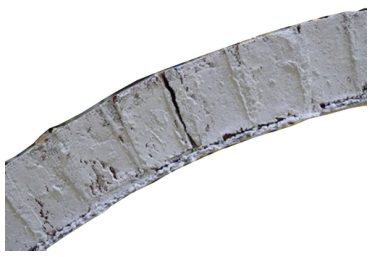

(a) Section 2

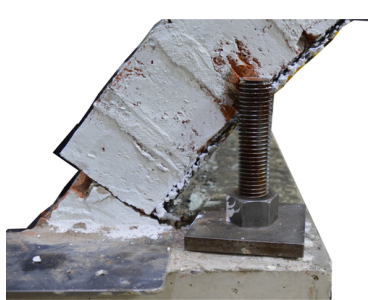

(d) Section 1

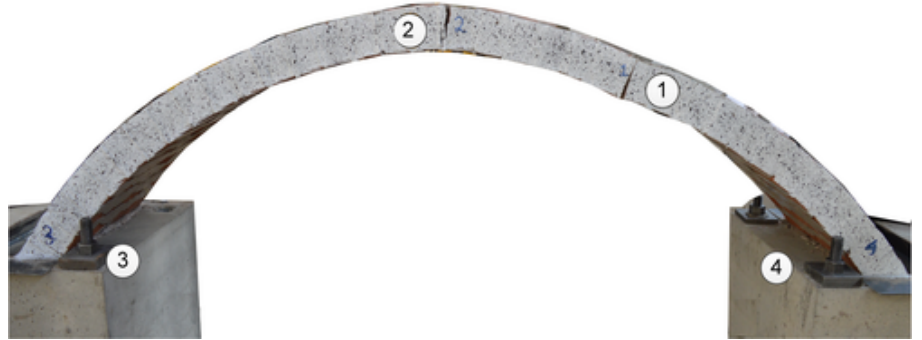

(b)

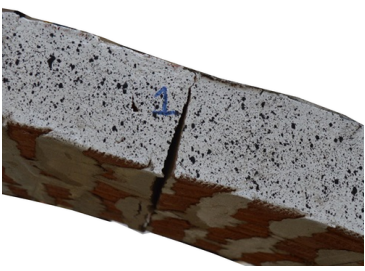

(c) Section 1

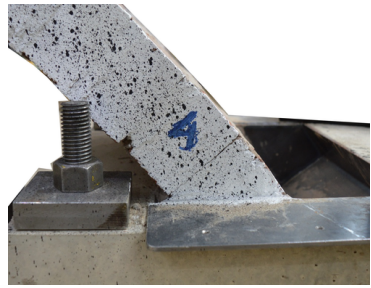

(e) Section 4

Figure 6: Collapse mechanism of control specimen

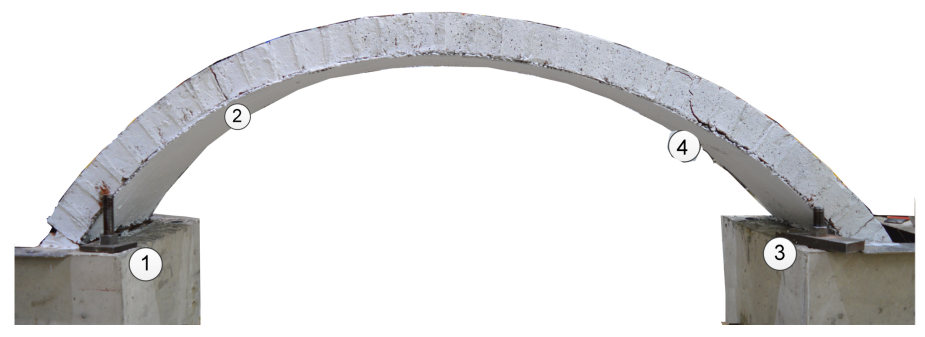

(b)

Figure 7: Collapse mechanism of specimen G3_I

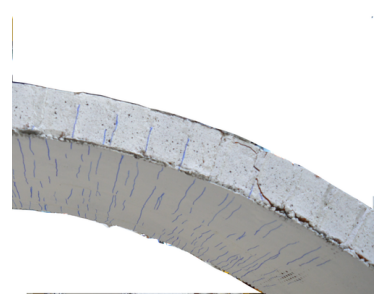

(c) Section 4

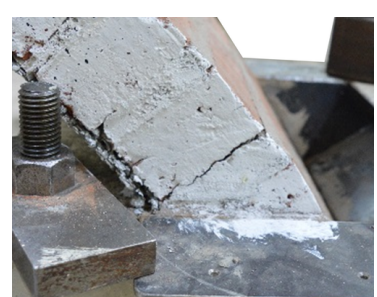

(e) Section 3 


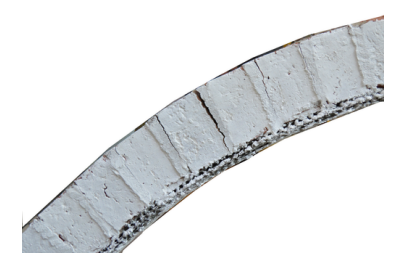

(a) Section 3

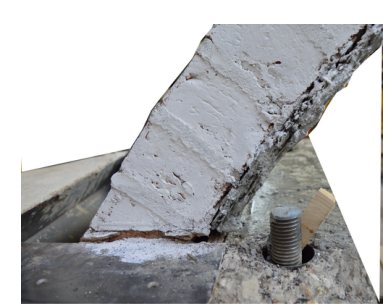

(d) Section 2

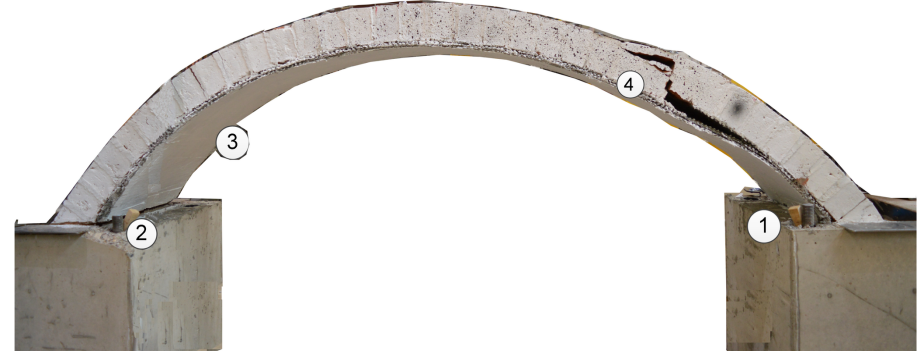

(b)

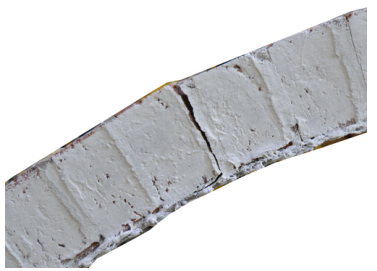

(a) Section 1

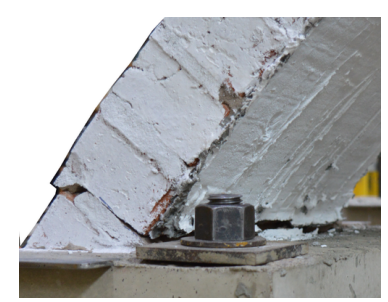

(d) Section 2

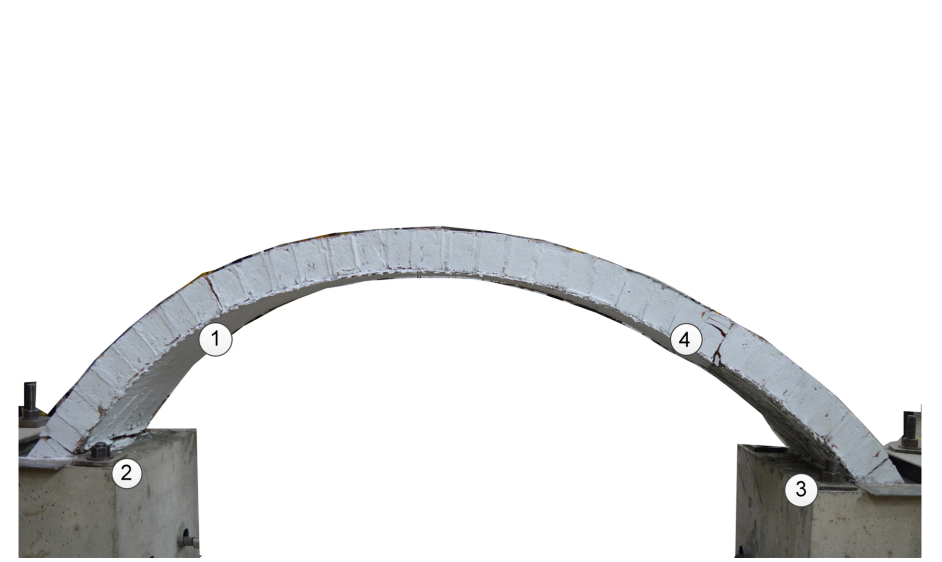

(b)

Figure 8: Collapse mechanism of specimen G7_I

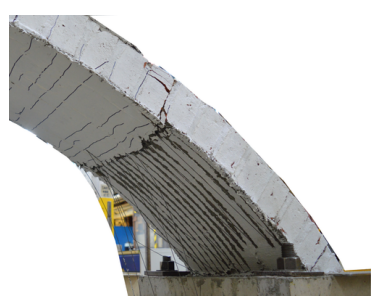

(c) Section 4

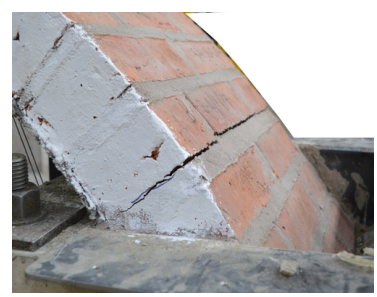

(e) Section 3

Figure 9: Collapse mechanism of specimen B3_I 


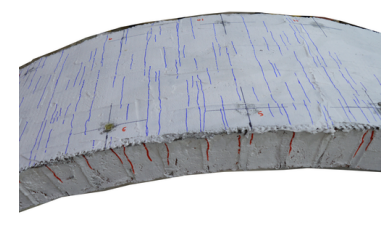

(a) Section 3

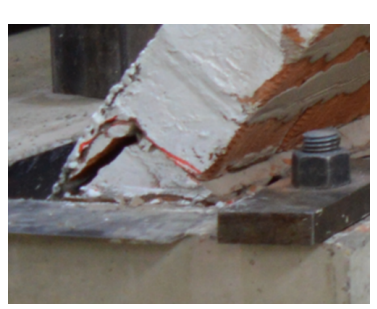

(d) Section 2

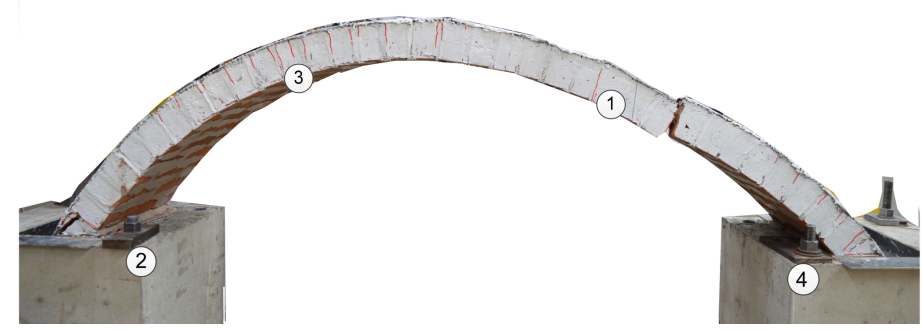

(b)

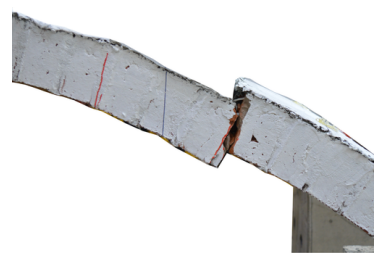

(c) Section 1

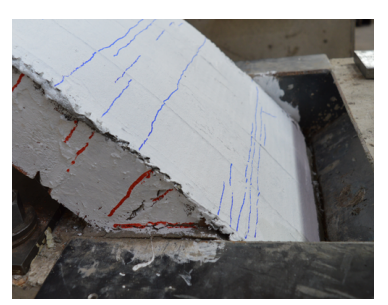

(e) Section 4

Figure 10: Collapse mechanism of specimen G3_E

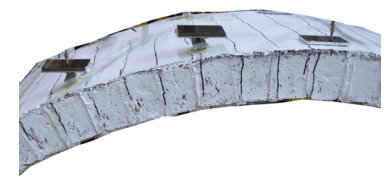

(a) Section 3
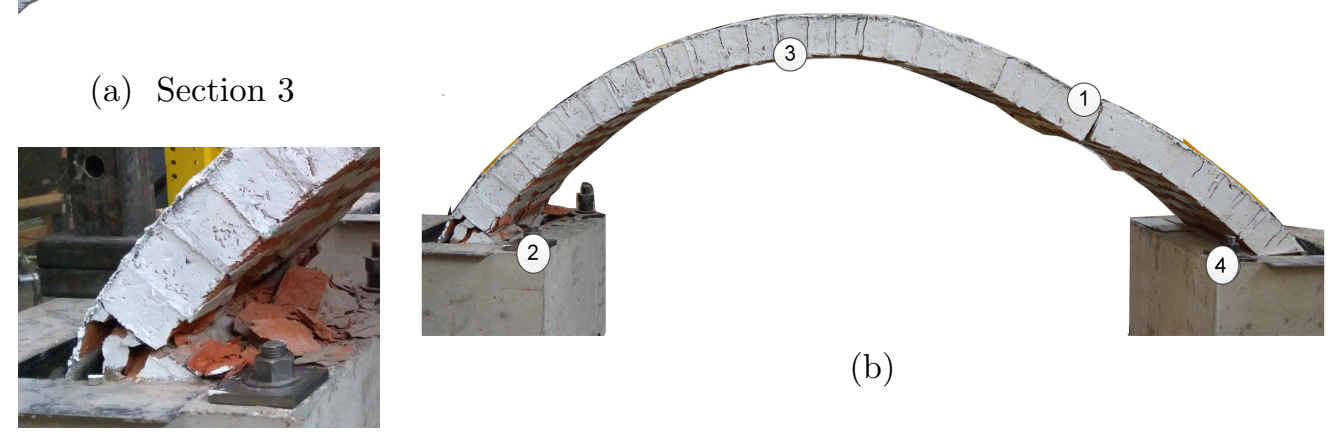

(b)

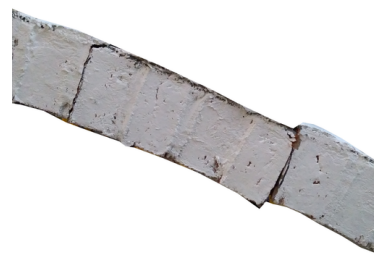

(c) Section 1

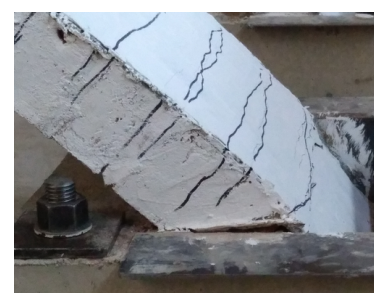

(e) Section 4

Figure 11: Collapse mechanism of specimen B3_E 


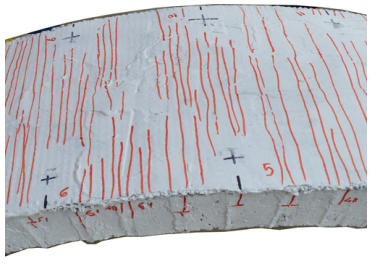

(a) Section 3

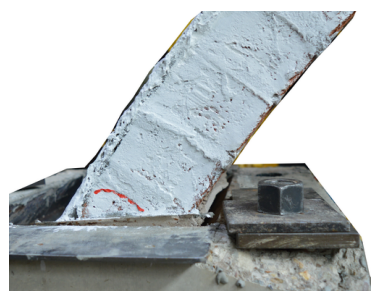

(d) Section 2

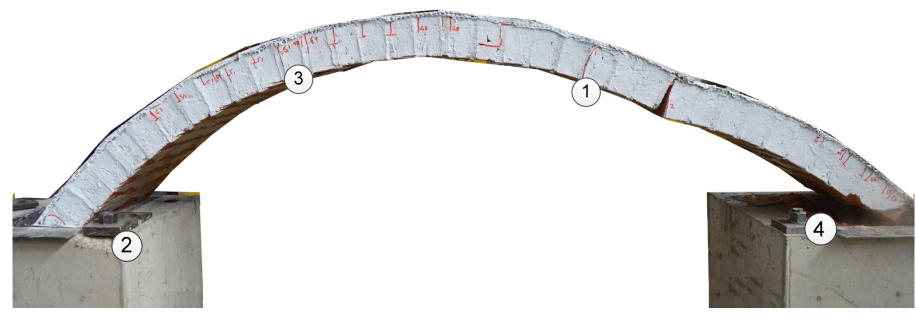

(b)

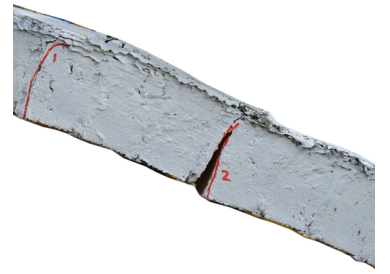

(c) Section 1

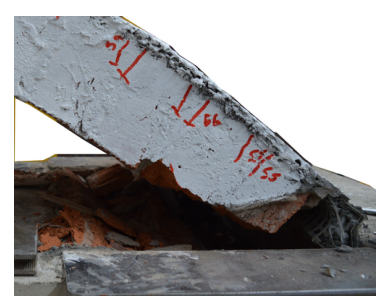

(e) Section 4

Figure 12: Collapse mechanism of specimen G7_E

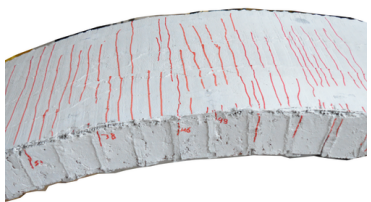

(a) Section 3

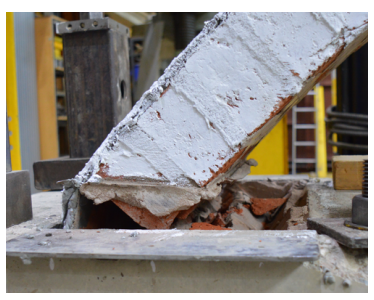

(d) Section 2

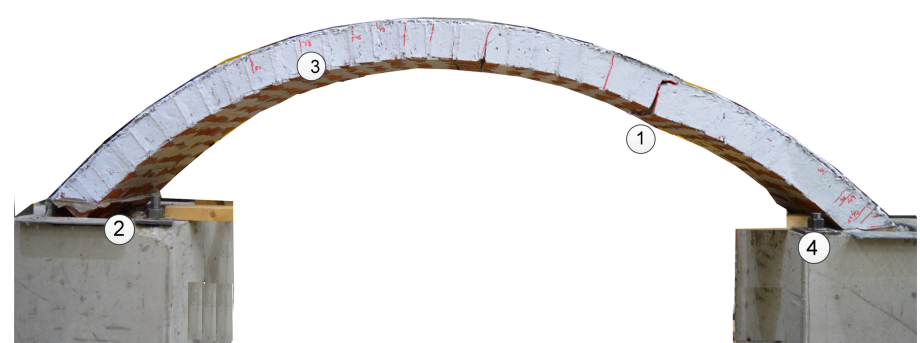

(b)

Figure 13: Collapse mechanism of specimen B7_E

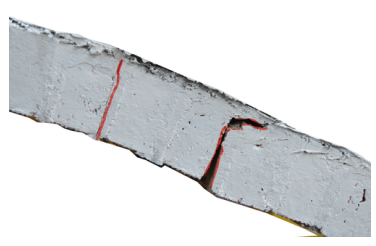

(c) Section 1

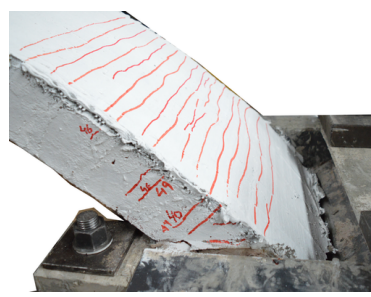

(e) Section 4 


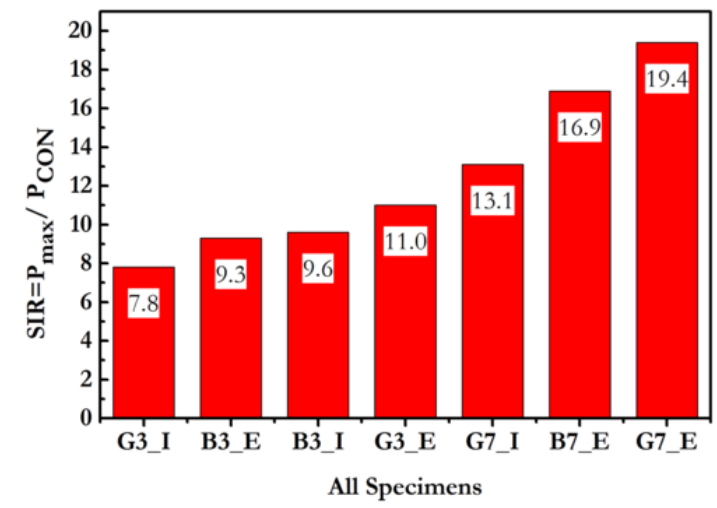

Figure 14: Ratio of the maximum strength effectiveness

correspond to different failure mechanisms. In B3_I, brick crushing and partial textile fracture occurred at $P_{\max }$, then followed by shear sliding whereas in G3_I shear sliding was observed at $P_{\text {max }}$ leading to immediate collapse. Brick crush-435 ing significantly altered the development length of sagging regions in the arch, (see Figs. 5d for B3_I and $5 \mathrm{~b}$ for G3_I, respectively) hence activating larger TRM lengths. Furthermore, the debonding of the TRM under the point load in G3_ $\mathrm{I}_{440}$ prevented the development of the masonry crushing zone and hints to poorer bonding conditions for the glass fibre textile.

Conversely, the larger development length of the TRM in the extrados region provided the nec-445 essary bond length to the glass fibre textile; this led to a better utilisation of the composite system stiffness and strength. The observed distribution of tensile cracks observed in the TRM surface of the coated glass specimens (G3_I, G3_E E50 $_{450}$ G7_E) was denser than the one observed in the coated basalt specimens (B3_I, B3_E, B7_E); this also highlights the improved bonding conditions in G3_E compared to B3_E.

In terms of deformation capacity, specimen\$455 B3_I, B3_E, and B7_E demonstrated increased values of displacement at the maximum load, i.e., by $25 \%, 41 \%$, and $26 \%$, respectively compared to their glass fibre strengthened counterparts, i.e., G3_I, G3_E, and G7_E (see also Fig. 15b). The460 enlarged value obtained in B3_E with respect to G3_E is attributed to the initiation of shear sliding at the first load drop $\left(\Sigma_{B 3_{E}}\right)$ of the left support in B3_E, which resulted in a less stiff strength-
${ }^{420}$ ening system as shown in the post-elastic part of the load displacement curve in Fig. 4d, The consistently larger values of $d_{\max }$ for the basalt fibre textile strengthened specimens are attributed to the coarser mesh size of the textile that allows for larger slippage within the mortar before bond is activated. It is of interest to note however that the overall effectiveness of both materials with respect to deformability as this is manifested by their corresponding DIRs (Table 4) is similar. This is consistent with the fact that the tensile strength and the axial stiffness of the glass and basalt TRM layers is equivalent (Table 3).

\subsection{The effect of number of layers}

The transition from 3 to 7 TRM layers in masonry arches resulted in similar enhancement of the load bearing capacity, irrespective of the strengthening configuration. In particular, specimens G7_I, G7_E, B7_E demonstrated increased values of $P_{\max }$ by $67 \%$ and $77 \%$, and $82 \%$ compared to specimens G3_I, G3_E, and B3_E, respectively (see also Fig. 16a). It is of interest to note that a similar trend has been reported in [30] for the case of out of plane flexure of plane masonry walls strengthened with 3 and 7 TRM layers.

The maximum load was increased substantially but not proportionally to the additional reinforcement used. Compared to the control specimen, all strengthened specimens demonstrated a substantial increase of the maximum attained load as manifested by the corresponding SIR factors shown in Fig. 14. Moving from 3 to 7 TRM layers resulted in increased values of $P_{\max }$ ranging from 1.67 times in the case of G3_I with respect to G7_I, 1.78 in the case of G3_E with respect to G7_E, and 1.81 times in the case of B3_E with respect to $\mathrm{B} 7 \mathrm{E}$ specimens (see Fig. 4c).

It is of interest to note that the increase achieved in the extrados glass and basalt specimens is practically identical. Since no textile rupture occurred, this trend is indicative of the beneficial effect of the improved mechanical interlock between the additional number of TRM layers that imposes the same improvement ratio in the two materials [36]. 


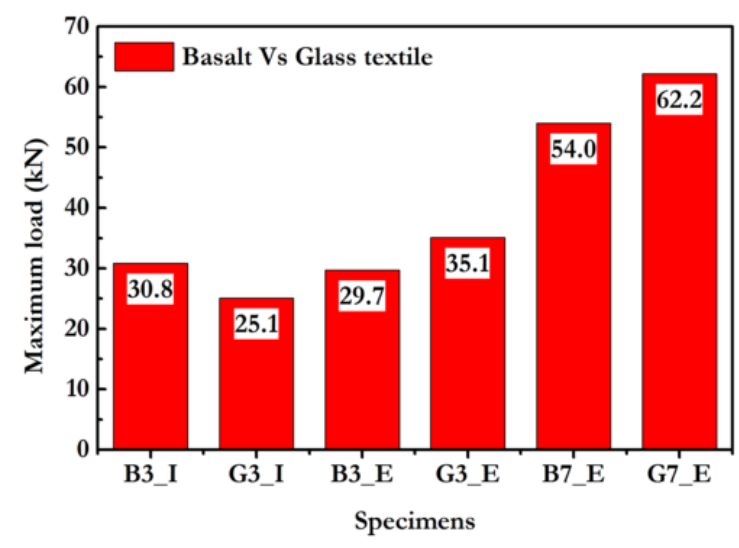

(a)

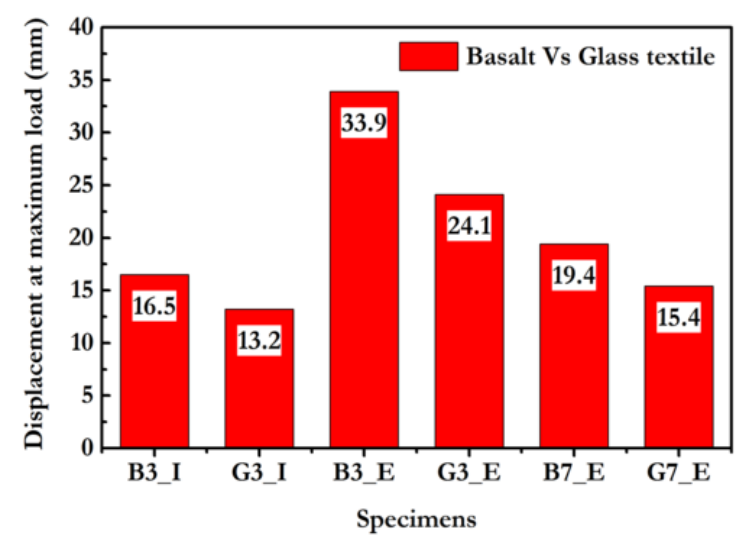

(b)

Figure 15: The effect of textile material in terms of (a) the maximum load and (b) the corresponding displacement

This increase however is not proportional to the increase in the amount of reinforcement used, i.e., $7 / 3=2.3$ times. All intrados and extrados strengthened specimens failed in a shear dominated mode both in the case of 3 and 7 TRM $_{500}$ layers. This highlights that the upper bound of the flexural strength of the arch has been reached even at the case of 3 layers of TRM (see also Fig. 16a) and justifies the fact that the 2.3 times increase in the amount of reinforcement resulted in505 a slightly reduced increase in $P_{\text {max }}$. Furthermore, in all cases the SIR values are much higher than the relative increase in the arch thickness due to the strengthening mortar alone. Hence we consider the effect of the high compressive strength mortar alone to be negligible, compared to thesio composite effect of the TRM.

The displacement at the maximum load of specimens G7_E and and B7_E decreased substantially by $36 \%$, and $43 \%$, with respect to specimens G3_E and B3_E, respectively (Fig. 16b). This is attributed to the increased axial stiffness provided by the seven TRM layers that resulted in increased tensile capacities at the hogging regions of the arch, effectively altering the failure mode to a shear dominated one. The increased num- ${ }^{520}$ ber of TRM layers resulted in a more distributed cracking pattern at the left haunch in specimens G7_E (Fig. 12a) and B7_E (Fig. 13a).

In specimen G7_I, the displacement at maxi-525 mum load was slightly lower, namely by $16 \%$ with respect to G3_I (Fig. 4f). Indeed, cracks on the TRM surface were more distributed in the latter (see, e.g., Fig. 7c) than in the former case (see, e.g., Fig. 8c). Similar to the extrados strengthening, the increase in the number of layers appears detrimental for the deformability of the specimens, see also Fig. 5; contrary to the extrados strengthening, the change in the number of layers did not alter the failure mechanism indicating that in this case 3 layers of textile reinforced fibre material already lead to an over-strengthened specimen with respect to flecture.

\subsection{The effect of the strengthening layout}

The strengthening layout had a significant impact on the effectiveness of the TRM composite and the corresponding failure mode. Masonry arches strengthened at the extrados with coated glass fibre-textile indicated higher $S I R$ and $D I R$ compared to the corresponding specimens strengthened at the intrados, as shown in Fig. 17. This was not the case for specimens strengthened with 3 TRM layers of coated basalt fibre-textile (B3_I, B3_E) where similar values of $P_{\max }$ were reported (see also Figs. 18, 14).

When the maximum load was attained both B3_I and B3_E demonstrated a significant shear sliding at the left support. In B3_I, this was followed by brick crushing (Fig. 9) that increased the active TRM region as discussed in Section 4.2 , conversely, in B3_E left support sliding was followed by shear sliding under the point load (see 


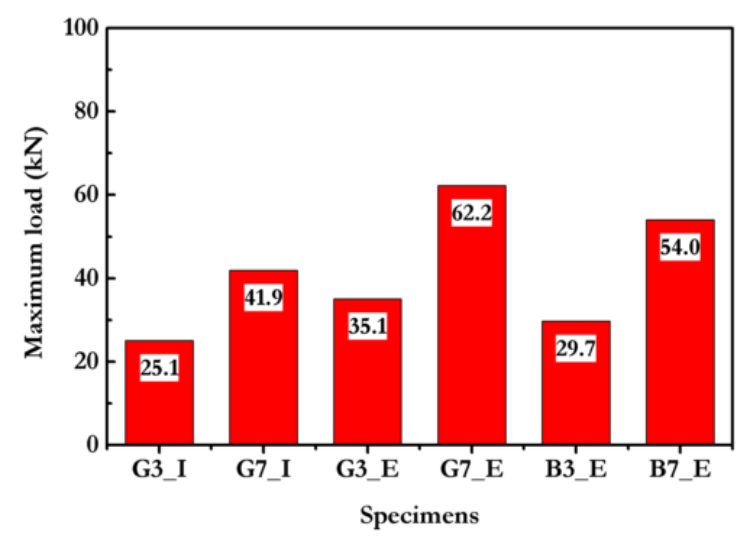

(a)

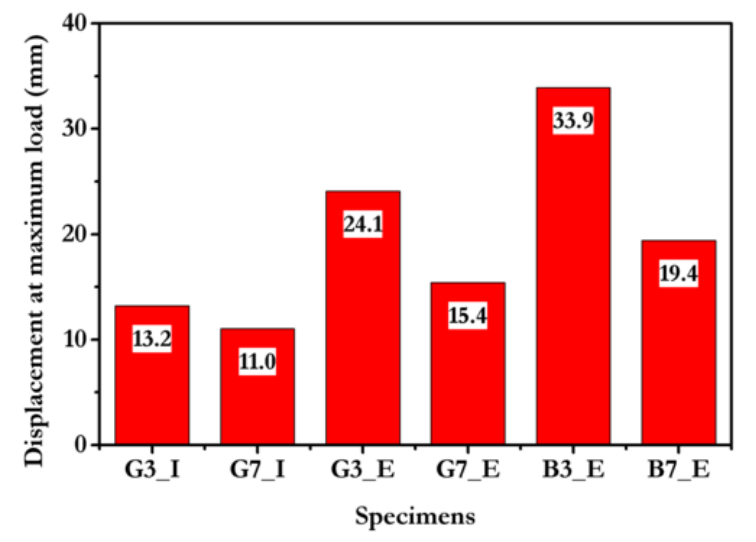

(b)

Figure 16: The effect of number of layers in terms of (a) the maximum load and (b) the corresponding displacement

Figs. 11) and the specimen failed pre-maturely without being able to reach the loads attained by the coated glass extrados specimens. We believe that the relatively large mesh spacing of the coated basalt textile has a detrimental impact on the bonding conditions achieved. Hence, further experimental work should be conducted to examine the bonding conditions and corresponding performance of the basalt textile fibre material. The improved performance of B7_E further supports this hypothesis, as it has been shown that increasing the number of textile fibre material layers enhances bonding through the action of the interlocking mechanism (see also discussion in Section 4.3.).

The highest $S I R$ observed in extrados strengthened coated glass specimens can be explained by observing the corresponding failure modes. In particular, the dominating failure mode in G3_I and G7_I was shear sliding followed by debond- ${ }^{560}$ ing of the TRM under the point load. However, in the case of G3_E and G7_E debonding did not occur hence the TRM was able to sustain additional load. Debonding was prevented due to better bonding conditions obtained by the increased ${ }^{565}$ anchorage length at the extrados with respect to the intrados. Specimens G3_E and G7_E attained increased values of the maximum load by $39.7 \%$ and $48.4 \%$, with respect to G3_I and G7_I, respectively (see also Fig. 18a and Table 4).

With regards to their deformation capacity

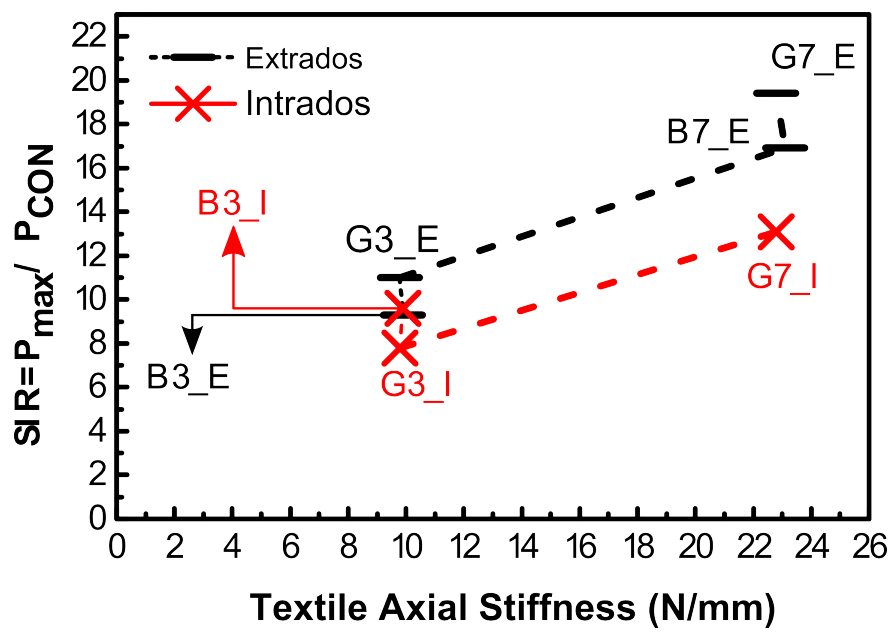

Figure 17: Ratio of the maximum strength effectiveness: Strengthening configuration

$d_{\text {max }}$, specimens B3_E, G3_E and G7_E demonstrated increased values by $105 \%, 83 \%$ and $40 \%$ respectively when compared to their corresponding intrados specimens, i.e., B3_I, G3_I, and G7_I respectively (see also, Fig. 18b). At $d_{\max }$, the collapse mechanism in all cases involves well developed sagging lengths which allow for larger portions of the TRM to be activated when this is placed at the extrados. The increased deformation capacity $\mathrm{d}_{u l t}$ mainly manifested at the extrados layout, highlights the capability of the TRM composite to delay brick separation along the mortar joints. Macroscopically, this enhances the deformability of the structure hence delaying collapse which can be beneficial especially for the 
case of earthquake excitation.

\section{Conclusions}

This study investigated the effect of the cementbased TRM strengthening system on medium- ${ }_{620}$ scaled masonry arches. The objective of this experimental campaign was to study the effect of i) the strengthening configuration; ii) the number of TRM layers; iii) coated glass and coated basalt fibre-textile composite, on the monotonically loaded TRM-strengthened masonry arches. 625

According to the analysed and discussed experimental results in terms of maximum load, deformation capacity and different failure modes conclusions are summarised as follows:

- By increasing the TRM layers from 3 to $7,{ }^{630}$ which is equal to 2.3 times, the maximum attained load increased by 1.7 and 1.8 times for the specimens strengthened at the intrados and extrados, respectively. The failure mechanism of shear sliding among the corresponding specimens indicated that after a certain amount of strengthening material, this system cannot be further enhanced unless shearing along the mortar joints is avoided.

- Increasing the amount of textile fibre material by 2.3 times resulted in decreased defor- ${ }^{640}$ mation capacities. This was mainly manifested at the extrados strengthened specimens where TRM development lengths were larger and is consistent with the increased $\mathrm{ax}^{-645}$ ial stiffness of the TRM strengthening layer and the resulting shear driven failure modes observed.

- Specimens strengthened at the extrados with coated glass textile fibre material outperformed the corresponding intrados strengthened specimens. TRM placed on the ex-655 trados results in larger development lengths and further improves the performance of hogging regions that are critical in this asymetric loading scenario.
- Specimens strengthened at the extrados with basalt textile fibre material resulted in practically identical SIRs compared to the corresponding intrados strengthened specimens. Given that the coated glass and basalt material parameters are practically identical, this result is indicative of reduced bonding conditions that are attributed to the large mesh size of the basalt textile fibre.

- Of interest is the improved load capacities of specimen B3_I compared to G3_I. B3_I was characterized by brick masonry crashing under the point load which proved beneficial as it increased the length of the sagging zones and inevitably led to enhanced utilisation of the TRM strengthening.

- All the extrados strengthened specimens demonstrated a significantly increased deformation capacities when compared to the intrados strengthened systems as manifested by the corresponding $D I R$ values. This was not the case for specimen G7_E, where the increase was less pronounced since the amount of TRM reinforcement resulted in a shear driven and hence brittle failure mode.

\section{References}

[1] T. F. Paret, S. A. Freeman, G. R. Searer, M. Hachem, U. M. Gilmartin, Using traditional and innovative approaches in the seismic evaluation and strengthening of a historic unreinforced masonry synagogue, Engineering Structures 30 (8) (2008) 2114-2126.

[2] M. Corradi, A. Borri, A. Vignoli, Experimental evaluation of in-plane shear behaviour of masonry walls retrofitted using conventional and innovative methods, Masonry International 21 (1) (2008) 29.

[3] P. Foraboschi, Strengthening of masonry arches with fiber-reinforced polymer strips, Journal of composites for construction 8 (3) (2004) 191-202.

[4] S. B. Bati, L. Rovero, Towards a methodology for estimating strength and collapse mechanism in masonry arches strengthened with fibre reinforced polymer applied on external surfaces, Materials and Structures 41 (7) (2008) 1291-1306.

[5] E. Hamed, O. Rabinovitch, Lateral out-of-plane strengthening of masonry walls with composite materials, Journal of Composites for Construction 14 (4) (2010) 376-387. 


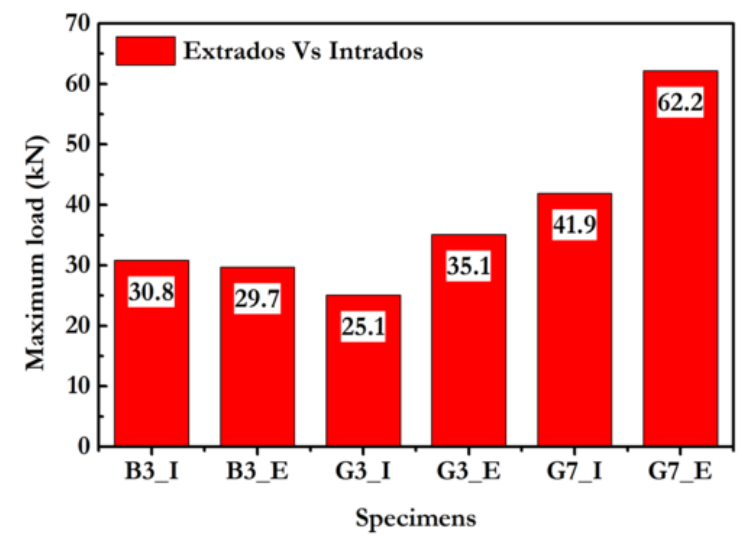

(a)

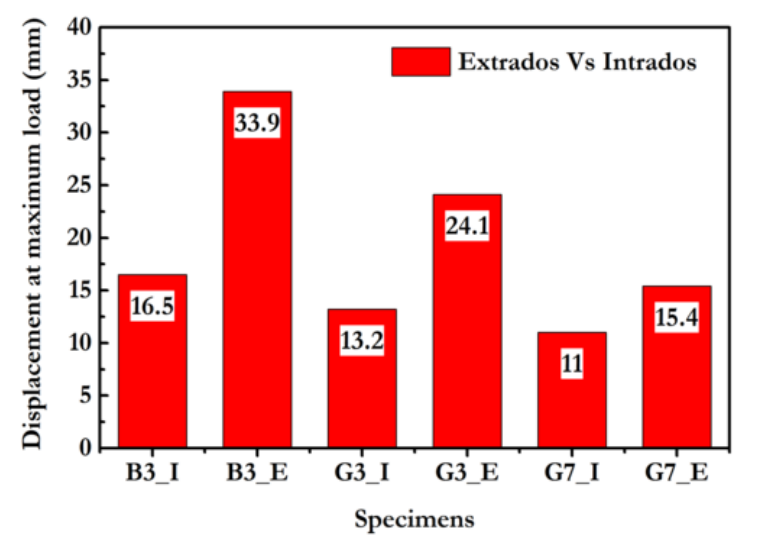

(b)

Figure 18: The effect of the strengthening configuration in terms of (a) the maximum load and (b) the corresponding displacement

[6] M. R. Valluzzi, M. Valdemarca, C. Modena, Behavior of brick masonry vaults strengthened by FRP laminates, Journal of Composites for Construction 5 (3)roo (2001) 163-169.

[7] D. V. Oliveira, I. Basilio, P. B. Lourenço, Experimental behavior of FRP strengthened masonry arches, Journal of Composites for Construction 14 (3) (2010) $312-322$.

[8] T. C. Triantafillou, Strengthening of masonry structures using epoxy-bonded FRP laminates, Journal of composites for construction 2 (2) (1998) 96-104.

[9] T. C. Triantafillou, M. N. Fardis, Strengthening of historic masonry structures with composite materials 710 Materials and Structures 30 (8) (1997) 486-496.

[15] L. Ascione, G. de Felice, S. De Santis, A qualification method for externally bonded Fibre Reinforced
Cementitious Matrix (FRCM) strengthening systems, Composites Part B: Engineering 78 (2015) 497-506.

[16] F. G. Carozzi, C. Poggi, Mechanical properties and debonding strength of Fabric Reinforced Cementitious Matrix (FRCM) systems for masonry strengthening, Composites Part B: Engineering 70 (2015) $215-230$.

[17] Z. C. Tetta, L. N. Koutas, D. A. Bournas, Shear strengthening of full-scale RC T-beams using textilereinforced mortar and textile-based anchors, Composites Part B: Engineering 95 (2016) 225-239.

[18] L. N. Koutas, Z. Tetta, D. A. Bournas, T. C. Triantafillou, Strengthening of Concrete Structures with Textile Reinforced Mortars: State-of-the-Art Review, Journal of Composites for Construction 23 (1) (2019) 03118001.

[19] L. A. S. Kouris, T. C. Triantafillou, State-of-the-art on strengthening of masonry structures with textile reinforced mortar (TRM), Construction and Building Materials 188 (2018) 1221-1233.

[20] R. Royles, A. Hendry, Model tests on masonry arches, in: Proceedings of the institution of Civil Engineers, Part 2, vol. 89, 299-321, 1991.

[21] L. Garmendia, P. Larrinaga, R. San-Mateos, J. T. San-Jose, Strengthening masonry vaults with organic and inorganic composites: an experimental approach, Materials and Design 85 (2015) 102-114.

[22] V. Alecci, F. Focacci, L. Rovero, G. Stipo, M. De Stefano, Extrados strengthening of brick masonry arches with PBO-FRCM composites: Experimental and analytical investigations, Composite Structures 149 (2016) 184-196.

[23] V. Alecci, M. De Stefano, F. Focacci, R. Luciano, L. Rovero, G. Stipo, Strengthening Masonry Arches with Lime-Based Mortar Composite, Buildings 7 (2) (2017) 49.

[24] E. Bertolesi, G. Milani, F. G. Carozzi, C. Poggi, An- 
cient masonry arches and vaults strengthened with TRM, SRG and FRP composites: Numerical analyses, Composite Structures 187 (2018) 385-402.

[25] A. Borri, P. Casadei, G. Castori, J. Hammond, Strengthening of brick masonry arches with externally bonded steel reinforced composites, Journal of composites for construction 13 (6) (2009) 468-475.

[26] Y. Tao, T. Stratford, J. Chen, Behaviour of a masonry arch bridge repaired using fibre-reinforced polymer composites, Engineering Structures 33 (5) (2011) 1594-1606.

[27] V. Alecci, F. Focacci, L. Rovero, G. Stipo, M. De Stefano, Intrados strengthening of brick masonry arches with different FRCM composites: experimental and analytical investigations, Composite Structures 176 (2017) 898-909.

[28] L. Garmendia, J. San-Jose, D. Garcia, P. Larrinaga, Rehabilitation of masonry arches with compatible advanced composite material, Construction and Building Materials 25 (12) (2011) 4374-4385.

[29] F. G. Carozzi, C. Poggi, E. Bertolesi, G. Milani, Ancient masonry arches and vaults strengthened with TRM, SRG and FRP composites: Experimental evaluation, Composite Structures 187 (2018) 466 - 480, ISSN 0263-8223.

[30] F. Kariou, S. Triantafyllou, D. Bournas, L. Koutas, Out-of-plane response of masonry walls strengthened using textile-mortar system, Construction and Building Materials 165 (2018) 769-781.

[31] F. A. Kariou, S. P. Triantafyllou, D. A. Bournas, L. N. Koutas, Out-of-plane behaviour of TRM strengthened masonry walls, in: Proceedings of the 4th conference on Smart Monitoring, Assessment and Rehabilitation of Civil Structures-SMAR, Zurich (Switzerland), 2017.

770 [32] P. Zampieri, N. Simoncelo, C. D. Tetougueni, C. Pellegrino, A review of methods for strengthening of masonry arches with composite materials, Engineering Structures 171 (2018) 154-169.

[33] BS, 772-1: Methods of test for masonry units - Part 1: Determination of compressive strength, British Standards Institute Limited

[34] EN, 1015-11, Methods of test for mortar for masonry - Part 11: Determination of flexural and compressive strength of hardened mortar, European Committee for Standardization, Brussels .

[35] C. EN, 1052-1: 1998-12 Methods of test for masonryPart 1: Determination of compressive strength, European Committee for Standardization, Brussels, Belgium .

[36] S. M. Raoof, L. N. Koutas, D. A. Bournas, Textilereinforced mortar (TRM) versus fibre-reinforced polymers (FRP) in flexural strengthening of RC beams, Construction and Building Materials 151 (2017) 279-291. 